\title{
Efficacy of pulmonary rehabilitation in patients with moderate chronic obstructive pulmonary disease: a randomized controlled trial
}

\author{
Miguel Román 1*, Concepción Larraz², Amalia Gómez³ , Joana Ripoll ${ }^{4}$, Isabel Mir ${ }^{5}$, Eduardo Z Miranda ${ }^{6}$, Ana Macho7,
} Vicenç Thomas ${ }^{8}$ and Magdalena Esteva ${ }^{4}$

\begin{abstract}
Background: Pulmonary Rehabilitation for moderate Chronic Obstructive Pulmonary Disease in primary care could improve patients' quality of life.

Methods: This study aimed to assess the efficacy of a 3-month Pulmonary Rehabilitation (PR) program with a further 9 months of maintenance (RHBM group) compared with both PR for 3 months without further maintenance (RHB group) and usual care in improving the quality of life of patients with moderate COPD.

We conducted a parallel-group, randomized clinical trial in Majorca primary health care in which 97 patients with moderate COPD were assigned to the 3 groups. Health outcomes were quality of life, exercise capacity, pulmonary function and exacerbations.

Results: We found statistically and clinically significant differences in the three groups at 3 months in the emotion dimension $(0.53$; $95 \% \mathrm{Cl} 0.06-1.01)$ in the usual care group, $(0.72 ; 95 \% \mathrm{Cl} 0.26-1.18)$ the RHB group $(0.87 ; 95 \% \mathrm{Cl} 0.44-1.30)$ and the RHBM group as well as in fatigue $(0.47 ; 95 \% \mathrm{Cl} 0.17-0.78)$ in the RHBM group. After 1 year, these differences favored the long-term rehabilitation group in the domains of fatigue $(0.56 ; 95 \% \mathrm{Cl} 0.22-0.91)$, mastery $(0.79 ; 95 \% \mathrm{Cl} 0.03$ $1.55)$ and emotion $(0.75 ; 95 \% \mathrm{Cl} 0.17-1.33)$. Between-group analysis only showed statistically and clinically significant differences between the RHB group and control group in the dyspnea dimension (0.79 95\%Cl 0.05-1.52). No differences were found for exacerbations, pulmonary function or exercise capacity.
\end{abstract}

Conclusions: We found that patients with moderate COPD and low level of impairment did not show meaningful changes in QoL, exercise tolerance, pulmonary function or exacerbation after a one-year, community based rehabilitation program. However, long-term improvements in the emotional, fatigue and mastery dimensions (within intervention groups) were identified.

Trial registration: ISRCTN94514482

Keywords: Chronic obstructive pulmonary disease, Pulmonary rehabilitation, Quality of life, Clinical trial, Primary care

\section{Background}

Chronic obstructive pulmonary disease (COPD) is a major, worldwide health problem. In Spain, COPD affects $10.2 \%$ of individuals aged $40-80$ years and is the fourth leading cause of death [1]. COPD is a progressive disease, with chronic and worsening air-flow limitation. In addition to pathological changes in the lungs, COPD has

\footnotetext{
* Correspondence: miguelroman@ibsalut.caib.es

'Primary Care Majorca Department, Son Pisà Primary Health Centre, C/ Vicenç Joan Perello Ribes, 65, Palma de Mallorca, Baleares, Spain

Full list of author information is available at the end of the article
}

been associated with extra-pulmonary manifestations which contribute to disease severity [2]. The only therapeutic measures that have proven effective in avoiding disease progression are smoking cessation and continuous home-based oxygen therapy in patients with hypoxemia $[3,4]$. Other treatments are associated with control of symptoms, such as improving dyspnea and patient quality of life, and avoiding exacerbations and hospitalizations.

Pulmonary rehabilitation (PR) is an evidence-based, multidisciplinary, comprehensive intervention for patients with chronic respiratory diseases who are symptomatic

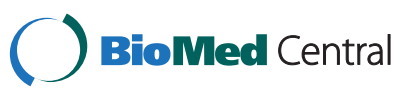


and often have progressively restricted daily-life activities. Pulmonary rehabilitation should be considered for all patients with chronic respiratory disease who have persistent symptoms, limited activity, and/or are unable to adjust to the illness despite otherwise optimal medical management. Gains can be achieved from pulmonary rehabilitation regardless of age, sex, lung function, or smoking status [5]. This comprehensive intervention has been clearly demonstrated to reduce dyspnea, improve exercise performance and health-related quality of life (HRQL), and is a significant component in the management of COPD [6]. Furthermore, an emerging literature is beginning to reveal its effectiveness in reducing health-care costs [7]. PR reduces hospital admissions and mortality compared with usual community care (no rehabilitation) in COPD patients following an exacerbation and appears to be a highly effective and safe intervention. In spite of these clear benefits, only a small proportion of COPD patients have access to PR programs. Data from Canada indicates that less than $1.2 \%$ of patients with COPD had access to a PR program per year [8].

PR can be delivered in a variety of structured programs that may themselves have an influence on the degree or duration of long-term benefit [5]. Principles of pulmonary rehabilitation apply regardless of location and it has been shown to be effective across various settings including outpatient and home-care [9-13]. Pulmonary rehabilitation delivered in a community setting has similar efficacy to that achieved in a more traditional hospital-based setting. The potential advantages of community PR programs include cost-effectiveness, a safe clinical environment and the availability of trained staff [5]. Some studies show longer-lasting benefits derived from home-based rather than hospital-based programs [14] along with evidence that they provide greater patient comfort and satisfaction [15].

Few studies of a multidisciplinary nature have been performed in the Primary Health Care setting. One integrated disease-management program (consisting of optimal medication, reactivation, education, and exacerbation management) was developed for primary care patients with COPD in the Netherlands resulting in improved QoL and decreased dyspnea one year after program completion [16]. Another nurse-led, multidisciplinary pulmonary rehabilitation program in primary health care in Sweden found no significant improvement in functional capacity and QoL but did find a reduction in exacerbations at 12 months following a 6-week program [17]. The choice of model will depend on local factors of convenience, existing availability of resources and incremental costs. Staff characteristics may be important in achieving optimal outcomes [18].

Other factors associated with PR programs remain uncertain, including the long-term preservation of benefits and their optimal duration. Various strategies have been tried to maintain the benefits of rehabilitation $[11,14,15]$.
Continuing rehabilitation for a prolonged period only seems to confer a small additional benefit and comparisons between 18-month and 3-months programs have not provided greater insight into the matter [19]. There have been other studies of specific maintenance interventions after a conventional course of rehabilitation but, as yet, there is no broad consensus as to their benefit [5].

We compared the efficacy of a 3-month PR program (education and supervised training) with or without further PR maintenance over 9 months in primary health care centers with that of usual care, with the aim of improving the quality of life of patients with moderate COPD.

\section{Methods \\ Design}

This study is a parallel-group, randomized clinical trial involving 3 groups of patients with moderate COPD. The first group received PR for 3 months and rehabilitation maintenance for 12 months (RHBM group). The second group received PR for 3 months without further maintenance (RHB group) and the third (control) group received routine care without rehabilitation (GC group). The study protocol has been published elsewhere [20].

\section{Selection of patients}

Patients were recruited by their family physician from 7 primary care practices in Palma de Mallorca, Spain, from July 2005 to March 2007. Patients were identified from both the health center COPD registry and from the results of spirometry performed at the participating health centers. Subjects were eligible if they were 35 to 74 years old, had moderate COPD according to the GOLD criteria and had post-bronchodilator results on most recent spirometry of FEV1/FVC $<0.7$, FEV1 values between $50 \%$ and $80 \%$ [2], and were either smokers or non-smokers. Subjects were excluded if they presented with any musculoskeletal conditions that prevented exercising and walking test assessments, or terminal illness or other severe disease at the time of enrollment. Identified patients attended an inclusion visit with a family physician researcher to check eligibility. During this visit they were asked for written informed consent prior to randomization and baseline measurements. Patient recruitment lasted 12 months.

\section{Intervention}

Patients in the two intervention groups participated in a PR program, delivered in two primary care health centers, consisting of three 60 -minute sessions each week for 3 months. The intervention involved groups of 5-10 patients. The sessions consisted of three types of interventions:

a) Education program. During weeks 1, 6, and 12, patients received a 45-minute education session on the anatomy and physiology of the respiratory 
system, the correct use of inhalers and brief counseling on smoking cessation.

b) Respiratory Physiotherapy. Each session included a series of exercises, lasting a total of 15 minutes and including self-conscious breathing control, diaphragmatic breathing control, and exercises for the chest wall and abdominal muscle walls.

c) Low intensity peripheral muscle training. Each session included abdominal and upper and lower limb exercises, shoulder and full arm circling, weight-lifting and other exercises. This training has been described previously [21] and used in other clinical trials $[22,23]$. Each exercise was repeated $8-$ 10 times over 45 minutes.

Programmed activities were supervised by two physiotherapists in two primary health centers. They were trained for 7 days in a hospital PR unit in Barcelona. The physiotherapist recorded patient attendance at each session.

After completing the 3-month PR program, patients in the RHBM group attended a weekly-session maintenance program, including both respiratory physiotherapy and low intensity peripheral muscle training, until the end of the program at 12 months. Patients in the RHB group participated in routine care with their physician and nurse.

\section{Control group}

These patients did not participate in either of the intervention programs; rather, they remained under the routine care of their general practitioner and nurse throughout.

\section{Randomization \& blinding}

After the inclusion visit and before baseline evaluation visit, subjects were randomly assigned to one of the three groups using a centrally administered, computer-generated block randomization scheme using blocks of 6 with EPIDAT, stratified according to participating site. The case manager subsequently informed patients of their group allocation at the end of the baseline visit. The baseline visit was scheduled when enough patients were recruited to begin a PR group. Health staff members involved in follow-up (a psychologist and a nurse) were blinded to patient assignment.

\section{Measurements}

Evaluation visits were scheduled at enrollment, baseline, and after 3 and 12 months by the study secretary. At each contact, reasons for not attending PR sessions and evaluation were collected. During the assessment visits, the Chronic Respiratory Questionnaire was completed by a psychologist. Subsequently, patients responded to the rest of the questionnaire and underwent the 6-minute walking test (6MWT) and spirometry under nurse supervision.

\section{Primary outcome variable}

The pre-specified primary outcome was the change in score on the Spanish validated version of the Chronic Respiratory Questionnaire (CRQ) [24]. Each of the 20 items, in 4 domains (dyspnea, fatigue, emotional function and mastery or level of control), was graded on a sevenpoint Likert scale. An average change in score per item of 0.5 represented minimal, clinically relevant improvement or worsening [25].

\section{Secondary outcome variables}

Pulmonary function tests included forced spirometry and reversibility test with salbutamol. According to ERS-ATS recommendations, we used a Datospir 120 spirometer and measured FVC, FEV1 and FEV1/FVC, with results compared to Roca-Separ Spanish-specific reference values [26].

Exercise tolerance was assessed through the 6MWT. Two tests were performed per session, with a rest of at least 30 minutes between tests and the best result was used for each patient [27]. During the test, oxygen saturation and heart rate were monitored using a portable saturation monitor. Tests were stopped if subjects experienced chest pain, mental confusion, intolerable dyspnea or oxygen saturation $<90$. The Borg dyspnea scale was completed before and after each 6MWT.

Any hospital admissions and visits to family physician due to COPD exacerbations. Exacerbation was defined as episodes of either dyspnea or dry or productive cough, whether sputum was purulent or not, which were treated with oral corticosteroids and/or antibiotics. Also treatments with antibiotics or corticosteroids. These variables were recorded at baseline and final visit. At the baseline visit, patients were asked about episodes during the 12 months before enrollment and, at the final visit, about episodes suffered during follow-up. This information was confirmed by a nurse researcher review of primary care and hospital medical records.

Others variables included group allocation; demographic variables such as sex, age, smoking habits and packs/year; treatments for COPD; and dyspnea, as measured by the Medical Research Council (MRC) [28].

\section{Sample size}

Sample size calculation was based on the difference in expected improvement in quality of life between the intervention RHBM group and the control group. This improvement was defined as the difference between the mean global score on the CRQ scale at baseline and postrehabilitation. Sample size was calculated with ENE program version 2.1, Glaxo SA. A difference of 10 (0.5 per item for 20 items) was recognized as the minimum, clinically relevant difference. With an $\alpha$ level of 0.05 , a 1-beta of 0.8 and a standard deviation of 17 [22], and anticipating a 
drop-out rate of $20 \%$, we planned to randomly assigned 56 subjects to each group.

\section{Statistical analysis}

All statistical analyses were carried out on a modified intention-to-treat basis with SPSS v.14. Some patients had difficulty in keeping evaluation appointments. Missing values at evaluation visits were substituted with basal values. However, the numbers of hospital admissions and exacerbations, and the usual treatment of patients, were not replaced by basal values and were scored as missing values.

To reduce bias caused by large withdrawal rate, we did sensitivity analysis. We performed per-protocol analysis, analysis with baseline values for missing data and analysis with multiple imputation for missing data. The three analyses gave the same results. Reported results are for analysis with baseline values replacing missing data.

The chi-square test was used to compare betweengroup smoking habits and health services utilization for COPD exacerbation. Comparisons of normal variables among the three groups were assessed by ANOVA together with the Tukey post-hoc test.

For the primary outcomes (Chronic Respiratory Questionnaire subscale score, pulmonary function and 6-minute walking) we calculated within-group differences from baseline and 95\%CI (with a fixed-effects regression model) adjusting for baseline scores using the treatment group as a predictor. Separate regression analyses predicted treatment differences at 3-month and 12-month evaluations. We conducted generalized linear models analyses (GLM) to estimate adjusted treatment differences and withingroup and between-group differences, and the Bonferroni test to compare between-group differences. For the secondary outcomes, we used Poisson regression to analyze exacerbation rates requiring hospitalization and negative binomial to estimate the other variables covering healthcare utilization data. All the analysis was two-tailed, with an alpha level of $5 \%$.

The study received the approval of the Baleares Ethics Committee and the Majorca Primary Care Research Committee.

\section{Results}

We identified 97 patients who met all inclusion criteria and none of the exclusion criteria. All agreed to participate. Allocation resulted in 32 subjects randomized to the control group, 33 to the RHB group and 32 to the RHBM group. For some patients, the lag time from enrollment to basal evaluation was longer than expected because basal evaluations did not start until a minimum number of subjects were gathered for a rehabilitation group. The mean interval-time for each group was: 87 days for the control group, 110 days for the RHB group and 94 days for the
RHBM group (Table 1). No significant between-group differences were found.

During that period some patients were lost and did not attend basal evaluation. Finally, 23 patients were included in the control group, 22 in the RHB group and 26 in the RHBM group; these patients were included in our analysis. Figure 1 summarizes the patient flow and follow-up evaluation. Some subjects withdrew between randomization and baseline evaluation and others were temporarily lost to follow-up, but were evaluated after 12 months. Subjects in the RHBM group attended an average of 25 sessions each, or $69.4 \%$ of the planned sessions during the first three months, and an average of 21 during the maintenance period, that is, $58.3 \%$ of the planned sessions. Subjects in the RHB group attended an average of 13 sessions, or $36.1 \%$ of the sessions over the 3 month period.

Patients' socio-demographic characteristics included in the analysis showed similar distributions among the three groups at baseline, with none of the parameters showing statistically significant differences (Table 1). Of the patients who withdrew, $82.5 \%$ were men with an average age of $62.1(\mathrm{SD}=15.9)$ years and a FEV1 of $60 \%(\mathrm{SD}=10.6)$. Disease severity and functional capacity, as well as CRQ scores, were also well balanced among the distinct intervention groups.

\section{Primary outcome}

Within-group comparison (Table 2) showed significant and clinically relevant improvements in CRQ emotion scores at 3 months in the two rehabilitation groups. These effects were maintained at 12 months in the RHBM group. Also, significant and clinically relevant improvements were observed in the RHBM group at 3 and 12 month follow-up for fatigue. However, in the mastery dimension, the improvement only reached significant and clinically relevant differences at 12 months in the RHBM group. Between-group comparisons included in Table 3 show significant differences between the control and RHM group at 3 months for dyspnea scores. Between-group changes for other CRQ dimensions scores were not significant and clinically unimportant. Per protocol analysis and multiple imputation of missing values generated the same results.

\section{Secondary outcomes}

All 3 groups maintained pulmonary function, with no relevant significant changes, at both time points (Table 2 and Table 3). No differences within or between groups were observed in the 6-MWT. As shown in Table 4, no statistically significant differences were noted in health care outcomes.

\section{Discussion}

Our study evaluated the long-term effects of a PR program in a community primary care setting with moderate 
Table 1 Characteristics of study participants at baseline

\begin{tabular}{|c|c|c|c|}
\hline & $\begin{array}{c}\text { Control } \\
\mathrm{n}(\%)\end{array}$ & $\begin{array}{l}\text { RHB } \\
\mathrm{n}(\%) \\
\end{array}$ & $\begin{array}{l}\text { RHBM } \\
\text { n (\%) }\end{array}$ \\
\hline Number of subjects & $23(32.4)$ & $22(31)$ & $26(36.6)$ \\
\hline \multicolumn{4}{|l|}{ Sex } \\
\hline Female & $4(17.4)$ & $4(18.2)$ & $5(19.2)$ \\
\hline Male & $19(82.6)$ & $18(81.8)$ & $21(80.8)$ \\
\hline \multicolumn{4}{|l|}{ Working } \\
\hline Yes & $5(22.7)$ & $6(27.3)$ & $7(26.9)$ \\
\hline \multicolumn{4}{|l|}{ Smoking habits } \\
\hline Smoker & $8(34.8)$ & $7(31.8)$ & $9(34.6)$ \\
\hline Never smoked & $2(8.7)$ & $0(0.0)$ & $1(3.8)$ \\
\hline Ex-smoker & $13(56.5)$ & $15(68.2)$ & $16(61.5)$ \\
\hline \multicolumn{4}{|l|}{ MRCs dyspnea score category } \\
\hline 0 & $11(47.8)$ & $7(31.8)$ & $4(15.4)$ \\
\hline 1 & $11(47.8)$ & $11(50.0)$ & $17(65.4)$ \\
\hline 2 & $1(4.3)$ & $2(9.1)$ & $5(19.2)$ \\
\hline 3 & $0(0.0)$ & $1(4.5)$ & $0(0.0)$ \\
\hline 4 & $0(0.0)$ & $1(4.5)$ & $0(0.0)$ \\
\hline $\begin{array}{l}\text { Lag time enrolment to basal/ } \\
\text { evaluation (days), mean (SD) }\end{array}$ & $\begin{array}{c}87.4 \\
(85.1) \\
\end{array}$ & $\begin{array}{c}110.1 \\
(103.2) \\
\end{array}$ & $93.8(89.5)$ \\
\hline Age (years), mean (95\%Cl) & $\begin{array}{c}63.4 \\
(60.4-66.4)\end{array}$ & $\begin{array}{c}64.1 \\
(59.9-68.2)\end{array}$ & $\begin{array}{c}64.9 \\
(62.1-67.7)\end{array}$ \\
\hline $\begin{array}{l}\text { Body Mass Index, mean } \\
(95 \% \mathrm{Cl})\end{array}$ & $\begin{array}{c}28.4 \\
(26.3-30.5) \\
\end{array}$ & $\begin{array}{c}27.6 \\
(25.4-29.9) \\
\end{array}$ & $\begin{array}{c}29.8 \\
(27.8-31.7)\end{array}$ \\
\hline \multicolumn{4}{|l|}{$C R Q$, mean $(95 \% C l)$} \\
\hline Fatigue & $\begin{array}{c}5.7 \\
(5.2-6.2) \\
\end{array}$ & $\begin{array}{c}5.3 \\
(4.8-5.7) \\
\end{array}$ & $\begin{array}{c}5.2 \\
(4.6-5.8) \\
\end{array}$ \\
\hline Mastery & $\begin{array}{c}6.3 \\
(5.7-7.0) \\
\end{array}$ & $7.2(6.3-8.1)$ & $7.2(6.2-8.2)$ \\
\hline Dyspnea & $\begin{array}{c}2.5 \\
(1.8-3.1)\end{array}$ & $\begin{array}{c}3.0 \\
(2.5-3.6)\end{array}$ & $\begin{array}{c}3.0 \\
(2.4-3.5)\end{array}$ \\
\hline Emotion & $\begin{array}{c}5.2 \\
(4.6-5.8)\end{array}$ & $\begin{array}{c}4.6 \\
(4.0-5.3)\end{array}$ & $\begin{array}{c}4.2 \\
(3.6-4.8)\end{array}$ \\
\hline
\end{tabular}

\begin{tabular}{lccc}
\hline $\begin{array}{l}\text { Pulmonary function mean } \\
(95 \% \mathrm{Cl})\end{array}$ & & & \\
\hline FVC (I) & 74.0 & 73.7 & 73.4 \\
& $(66.5-81.5)$ & $(66.4-81.0)$ & $(67.2-79.6)$ \\
\hline FEV1 (I) & 60.1 & 59.9 & 60.9 \\
& $(55.6-64.4)$ & $(54.9-64.8)$ & $(56.3-65.5)$ \\
\hline FEV1/FVC & 59.1 & 60.8 & 61.2 \\
& $(54.5-63.1)$ & $(56.5-65.1)$ & $(58.6-63.8)$ \\
\hline Walking test (m), mean & 436.2 & 466.7 & 450.7 \\
(95\%Cl) & $(402.8-$ & $(432.0-501.5)$ & $(413.4-488.1)$ \\
& $469.6)$ & & \\
\hline
\end{tabular}

\section{COPD exacerbation}

hospitalization

\begin{tabular}{lccc}
\hline Yes $n(\%)$ & $5(21.7)$ & $5(22.7)$ & $3(11.5)$ \\
\hline mean $(95 \% \mathrm{Cl})$ & 0.6 & 0.8 & 1.2 \\
& $(0.01-1.2)$ & $(-0.1-1.8)$ & $(0.21-2.19)$ \\
\hline
\end{tabular}

COPD exacerbation visit to family physician

\begin{tabular}{llll}
\hline Yes $n(\%)$ & $12(52.2)$ & $9(40.9)$ & $7(28)$ \\
\hline
\end{tabular}

Table 1 Characteristics of study participants at baseline (Continued)

\begin{tabular}{lccc}
\hline mean $(95 \% \mathrm{Cl})$ & 3 & 0.5 & 0.5 \\
& $(-2.4-8.4)$ & $(-0.01-0.9)$ & $(-0.04-0.9)$ \\
\hline $\begin{array}{l}\text { COPD treatment with } \\
\text { antibiotics or corticoids }\end{array}$ & & & \\
\hline Yes n (\%) & $11(50)$ & $8(36.4)$ & $9(36)$ \\
\hline mean (95\%Cl) & 0.6 & 0.8 & $1.2(0.2-2.2)$ \\
& $(0.01-1.2)$ & $(-0.1-1.7)$ & \\
\hline
\end{tabular}

$\mathrm{I}=$ litres; $\mathrm{m}=$ meters; $\mathrm{Cl}=$ Confidence Interval; $\mathrm{X}^{2}$ for categorical variables and ANOVA for continuous variables.

No significant between-group differences were found for any of the variables.

COPD patients. All the groups that took part in PR showed a significant improvement in the emotional dimension after 3 months. This improvement was only maintained in the group that completed the one-year maintenance PR program but not in the 3-month intervention group. Benefits in the fatigue and mastery dimensions also observed after one year of program maintenance were not achieved in the other 2 comparison groups. Lack of improvement in exercise tolerance and overall QoL ratings between groups did not allow accurate determination of PR short- and long-term effectiveness.

Previous studies reported that emotional improvement after the intervention was not maintained after discontinuation or not even after complete PR maintenance programs [29,30], being the first deteriorated QoL dimension. Our results are in line with those reported by Moullec and Chavannes where PR maintenance strategies carried out in the community were associated with long-term improvements in QoL [16,31]. Emotional benefits were observed in both PR groups at 3 months and persisted in the group that continued pulmonary rehabilitation together with improvements in two domains that include sociopsychological components. One explanation could be the beneficial results of mixing with individuals with similar problems and sharing negative experiences with disease. The social support of other COPD patients and the longterm attention of a physiotherapist would promote a reduction in emotional reactions and development of adapted behaviors [31].

Otherwise, between-group findings are not in line with the results of Lacasse et al. meta-analysis [6], as we were not able to find a consistent improvement in any qualityof-life dimension. The patient's QoL was generally good at baseline and therefore had little scope to show large improvements through low intensity PR activities. Only dyspnea improved significantly after 3 months of PR in the RHB group compared to controls. This results could appear paradoxical given the very low attendance rate (36\%) in this group; much lower than the RHBM group (69\%). Patients showed a low baseline level of dyspnea in the MRC scale and high exercise capacity in the 6MWT. In fact, 22 patients had dyspnea with intense exercise 


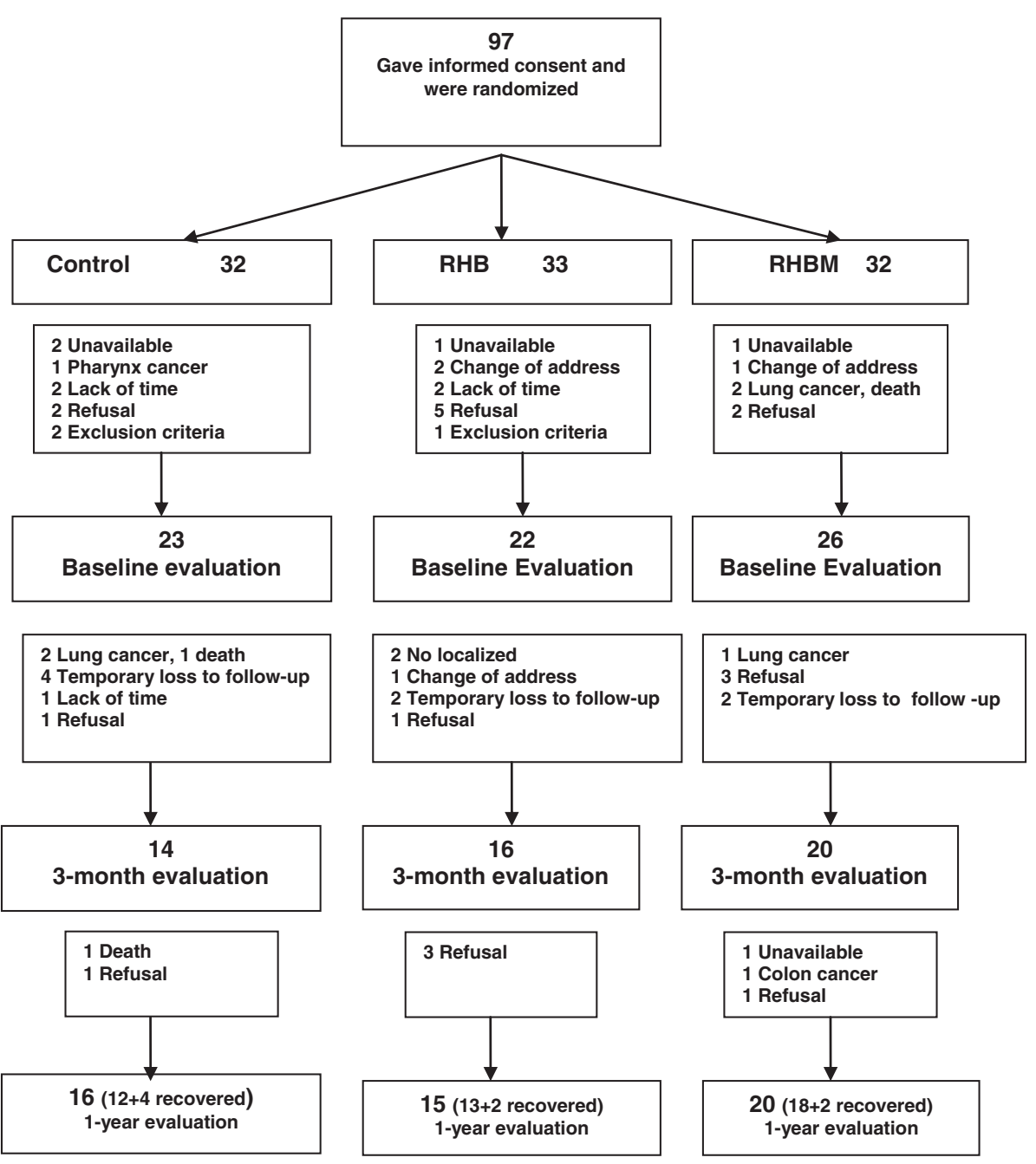

Figure 1 Study design.

Table 2 Chronic respiratory questionnaire subscale score, pulmonary function and 6-minute walking test differences from baseline to 3 and 12 months

\begin{tabular}{|c|c|c|c|c|c|c|}
\hline & \multicolumn{2}{|c|}{ Control $n=23$} & \multicolumn{2}{|c|}{ RHB $n=22$} & \multicolumn{2}{|c|}{ RHBM $n=26$} \\
\hline & 3 months & 12 months & 3 months & 12 months & 3 months & 12 months \\
\hline \multicolumn{7}{|l|}{ CRQ } \\
\hline Fatigue & $0.4(-0.05-0.7)$ & $0.2(-0.1-0.6)$ & $0.03(-0.3-0.4)$ & $0.3(-0.1-0.6)$ & $0.5(0.2-0.8)^{*}$ & $0.56(0.2-0.9)^{*}$ \\
\hline Mastery & $-0.6(-1.1--0.1)^{*}$ & $0.3(-0.5-1.2)$ & $-1.01(-1.5--0.5)^{*}$ & $0.01(-0.8-0.8)$ & $-0.3(-0.8-0.15)$ & $0.79(0.03-1.5)^{*}$ \\
\hline Dyspnea & $-0.5(-0.9--0.1)^{*}$ & $-0.4(-0.8-0.01)$ & $0.3(-0.1-0.7)$ & $0.07(-0.3-0.5)$ & $-0.2(-0.6-0.2)$ & $-0.23(-0.6-0.1)$ \\
\hline Emotion & $0.5(0.06-1.01)^{*}$ & $0.00(-0.6-0.6)$ & $0.7(0.3-1.2)^{*}$ & $0.5(-0.13-1.11)$ & $0.9(0.5-1.3)^{*}$ & $0.7(0.2-1.3)^{*}$ \\
\hline FVC (I) & $-1.5(-4.7-1.7)$ & $1.42(-2.4-5.3)$ & $0.5(-2.8-3.9)$ & $3.0(-1.04-7.05)$ & $-2.4(-5.5-0.6)$ & $-0.9(-4.7-2.7)$ \\
\hline FEV1 (I) & $0.8(-2.5-4.2)$ & $-0.22(-1.3-0.9)$ & $-0.03(-3.5-3.5)$ & $-0.1(-1.3-0.9)$ & $-2.1(-5.3-1.1)$ & $-1.2(-2.2--0.1)^{*}$ \\
\hline FEV1/FVC & $0.8(-1.9-3.6)$ & $3.03(0.6-5.5)^{*}$ & $-0.5(-3.3-2.2)$ & $-1.8(-4.3-0.6)$ & $-0.3(-2.8-2.2)$ & $-0.08(-2.3-2.1)$ \\
\hline Walking test $(\mathrm{m})$ & $27.3(4.4-50.3)^{*}$ & $33.2(8.2-58.3)^{*}$ & $0.9(-22.6-24.3)$ & $20.2(-5.3-45.8)$ & $19.5(-2.07-41.1)$ & $19.7(-3.8-43.3)$ \\
\hline
\end{tabular}

Within-group differences from baseline $(95 \% \mathrm{Cl})$.

${ }^{*} \mathrm{P}<0.05$. Values are means and $95 \% \mathrm{Cl}$ 's. A difference greater than 0.5 (improvement) or greater than -0.5 (deterioration) in CRQ scores, is considered clinically important.

$\mathrm{m}=$ meters. 
Table 3 Chronic respiratory questionnaire subscale score, pulmonary function and 6-minute walking test differences from baseline to 3 and 12 months

\begin{tabular}{lcccccc}
\hline \multicolumn{7}{c}{3 months } \\
\hline & RHB-Control $n=23$ & RHBM-Control $n=22$ & RHBM-RHB $n=26$ & RHB-Control $n=23$ & RHBM-Control $n=22$ & RHBM-RHB $n=26$ \\
\hline CRQ & & & & & & \\
\hline Fatigue & $-0.3(-0.9-0.2)$ & $0.09(-0.5-0.6)$ & $0.4(-0.1-0.9)$ & $0.02(-0.6-0.6)$ & $0.3(-0.3-0.9)$ & $0.3(-0.3-0.9)$ \\
\hline Mastery & $-0.4(-1.3-0.5)$ & $0.3(-0.5-1.1)$ & $0.7(-0.1-1.5)$ & $-0.3(-1.8-1.1)$ & $0.4(-0.9-1.8)$ & $0.8(-0.6-2.1)$ \\
\hline Dyspnea & $0.8(0.05-1.5)^{*}$ & $0.3(-0.4-0.9)$ & $-0.5(-1.2-0.2)$ & $0.5(-0.2-1.1)$ & $0.1(-0.5-0.8)$ & $-0.3(-0.9-0.3)$ \\
\hline Emotion & $0.2(-0.6-0.9)$ & $0.3(-0.5-1.1)$ & $0.1(-0.6-0.9)$ & $0.5(-0.6-1.6)$ & $0.7(-0.3-1,8)$ & $0.3(-0.8-1.3)$ \\
\hline FVC (I) & $2.05(-3.7-7.8)$ & $-0.9(-6.4-4.5)$ & $-2.9(-8.6-2.6)$ & $1.6(-5.2-8.4)$ & $-2.4(-8.9-4.1)$ & $-3.9(-10.7-2.7)$ \\
\hline FEV1 (I) & $-0.9(-6.8-5.04)$ & $-2.9(-8.6-2.7)$ & $-2.05(-7.8-3.7)$ & $0.07(-1.8-1.9)$ & $-0.9(-2.8-0.9)$ & $-1.04(-2.9-0.8)$ \\
\hline FEV1/FVC & $-1.4(-6.1-3.4)$ & $-1.12(-5.7-3.4)$ & $0.2(-4.3-4.8)$ & $-4.8(-9.1--0.6)^{*}$ & $-3.1(-7.2-0.9)$ & $1.7(-2.3-5.8)$ \\
\hline Walking test $(\mathrm{m})$ & $-26.4(-66.5-13.6)$ & $-7.8(-46.3-30.7)$ & $18.6(-20.3-57.8)$ & $-12.9(-56.7-30.7)$ & $-13.5(-55.5-28.5)$ & $-0.5(-43.02-41.9)$ \\
\hline
\end{tabular}

${ }^{*} \mathrm{P}<0.05$. Values are means and $95 \% \mathrm{Cl}$ 's. A difference greater than 0.5 (improvement) or greater than -0.5 (deterioration) in CRQ scores, is considered clinically important.

Between-group differences (RHB group minus control group, RHBM minus control, RHBM-RHB).

(MRC 0); of the 47 patients with higher scores, only $17 \%$ had a MRC scale score $>1$.

In common with most PR studies conducted on COPD patients, we found no improvements in pulmonary function parameters $[10,21,32]$. Our patients following the rehabilitation program did not show significant improvements in exercise capacity in contrast to those described in a previous meta-analysis [6], and in a more recent study [33] where PR, including a much more intensive exercise such as endurance training, was highly effective in improving the exercise capacity of patients with COPD. Our RHB program included low intensity peripheral muscle training but did not have any endurance training which could explain this lack of effect. As mentioned above, we included patients with a high

Table 4 Use of health services due to COPD exacerbations at 12 months

\begin{tabular}{lccc}
\hline & \multicolumn{3}{c}{ 12-month evaluation } \\
\cline { 2 - 4 } & Control & RHB & RHBM \\
\hline COPD exacerbation hospitalization & & & \\
\hline Yes $\mathrm{n}(\%)$ & $3(15.8)$ & $5(22.7)$ & $3(12.5)$ \\
\hline mean (Cl 95\%) & 0.2 & 0.2 & 0.1 \\
& $(-0.05-0.5)$ & $(-0.04-0.4)$ & $(-0.02-0.3)$ \\
\hline COPD exacerbation visit to & & & \\
family physician & & & \\
\hline Yes n (\%) & $9(42.8)$ & $7(35)$ & $7(30.3)$ \\
\hline mean (Cl 95\%) & 0.8 & 0.7 & 0.8 \\
& $(0.1-1.4)$ & $(0.1-1.4)$ & $(0.2-1.4)$ \\
\hline COPD treatment with antibiotics & \multicolumn{3}{c}{} \\
or corticoids & \multicolumn{3}{c}{} \\
\hline Yes n (\%) & $6(33.4)$ & $5(26.3)$ & $4(20)$ \\
\hline mean (Cl 95\%) & 1.08 & 0.3 & 0.7 \\
& $(0.2-1.9)$ & $(-0.04-0.7)$ & $(0.1-1.2)$ \\
\hline
\end{tabular}

No significant between-group differences were found for any of the variables. exercise capacity with a mean walking distance between 436 and 466 meters while the Italian study baseline mean distance was around 300 meters [33].

By selecting patients with low basal symptoms, the effectiveness of the intervention can be limited as described by others [17]. These findings suggest that the greatest room for improvement in primary care patients can be expected in those with tangible dyspnea and impaired health status (MRC score $>2$ and/or CCQ score $>1$ ) across all GOLD stages $[16,34]$.

We found that the proportions of individuals with some exacerbation episodes were similar in the three groups, in agreement with previous studies [35,36], while a recent PR primary care program found a reduction in exacerbation rate after a community PR program [17].

Most PR programs are based at hospitals or at home $[10-12,14,33,37]$. The intervention we evaluated was developed in primary care centers, with the existing resources of those health centers. In so doing, we attempted to show that this intervention was feasible in a setting where PR is not a regular service but highly accessible for patients. Few PR integrated community programs have been developed with primary care resources and though they found benefits, the results are not conclusive $[16,17]$. Low patient compliance with the intervention indicates the need for a more integrated approach in order to involve patients as active partners in their treatment process and achieve positive results in behavior modification $[31,38]$.

Our study showed persistent within-group improvements in QoL after only a 1-year maintenance program, with no similar effects in the 3-month program group. At this moment it is not known how long these programs should take and how they might influence behavior [38] or whether alternative management such as an action-plan or self-management strategies could result 
in important long-term benefits [32,39]. It is generally believed that longer programs yield more durable training effects but the majority of existing studies looking for long-term results, such as ours, have shown small improvements which may not always be possible to replicate $[11,15-17,19,23,32,34]$.

\section{Limitations}

One important limitation arises from the fact that we were not able to recruit the sample size required. Even with active review of included-centers' registers and COPD patients records, fewer patients than expected were identified. This is consistent with the results of other studies showing COPD under-reporting [40] and the difficulties of recruiting patients with COPD to a PR trial. This affected the power of the study to identify significant changes in the PR groups and led to negative results.

The high rate of withdrawal was also an obstacle to obtaining fair results. Of the patients initially included, almost 50\% withdrew after randomization and the remainder showed moderate adherence to PR sessions. These two limitations reduced the power of this study to identify PR benefits. The characteristics of patients lost after initial evaluation did not differ significantly among the three randomized groups, indicating that loss to follow-up did not alter our final results.

In analyzing the factors related to non-adherence, we found that one of the primary health care centers was located far from the city center thus limiting accessibility to patients living far away. Low adherence during the second year of PR in our first cohort study resulted in a deviation from protocol, which was designed to evaluate the long-term (24-month) effect of PR maintenance. Patient withdrawal due to morbidity and mortality also had a negative influence on our final sample. Most studies analyzing similar rehabilitation programs in COPD patients have also shown considerable loss to follow-up, even higher than ours $[15,41,42]$. In addition, the PR provided in groups of patients probably made it more difficult to adapt to the timetable than if it were performed individually and, as such, influenced adherence to PR sessions.

\section{Conclusions}

We found that patients with moderate COPD and low level of impairment did not show meaningful changes in QoL, exercise tolerance, pulmonary function or exacerbation after a one-year, community-based rehabilitation program. However, long-term improvements in the emotional, fatigue and mastery dimensions were identified. COPD is a disease in which most interventions, including pharmacological interventions, produce low levels of benefits that do not lead to quality of life improvements and a reduction in exacerbations. The selection of patients for community-based rehabilitation programs should be based on level of impairment and regular symptoms. The maintenance of benefits is highest in the group which completed the entire 12-month intervention although the long-term effects of PR programs is still unknown and more studies are needed to establish the optimum duration and nature of maintenance programs. These benefits are less evident in patients with moderate COPD.

\section{Competing interest}

The authors' declare that they have no competing interests.

\section{Authors' contribution}

$M R, C L, A G$ and ME designed the study. ME and JR designed the questionnaires, coordinated trial field-work, acquisition of data and follow-up. IM and EZM elaborated the intervention, wrote the intervention leaflet and supervised physiotherapists. JR and ME did the statistical analysis and interpretation of data. MR, CL, ME, JR and AG wrote the paper. All authors provided critical revision for intellectual content, contributed to the writing of and approved the final paper.

\section{Acknowledgements}

This study was made possible by the dedication of our staff: We are grateful to Maria Perelló, the secretary of the study Central Office; to the physicians, nurses and psychologists at the Respiratory Unit, Hospital General de Mallorca; and to Rosa Güell and colleagues from the Respiratory

Rehabilitation Unit, Hospital Clínic, Barcelona. We also thank physiotherapists C. Rueda and A. Miranda, who worked with patients in such a sensitive way. Last but not least, we thank Alfonso Leiva for his valuable comments on the manuscript and Teresa Estrades.

This study was supported by a grant from the Marató de TV3 (no 04-2610), by the University Institute of Health Sciences (IUNICS). In addition, the study has received support from the Heath Promotion and Preventive Activities Network RD06/0018/0036 accredited by the Instituto Carlos III of the Ministry of Health.

\section{Author details}

${ }^{1}$ Primary Care Majorca Department, Son Pisà Primary Health Centre, C/ Vicenç Joan Perello Ribes, 65, Palma de Mallorca, Baleares, Spain. ${ }^{2}$ Primary Care Majorca Department, Escuela Graduada Primary Health Centre, Palma de Mallorca, Baleares, Spain. ${ }^{3}$ Primary Care Majorca Department, Coll d'en Rabassa Primary Health Centre, Palma de Mallorca, Baleares, Spain. ${ }^{4}$ Primary Care Majorca Department, Unit of Research, Palma de Mallorca, Baleares, Spain. ${ }^{5}$ Primary Care Majorca Department, Hospital Son Llàtzer, Unit of Pneumology, Palma de Mallorca, Baleares, Spain. ${ }^{6}$ Primary Care Majorca, Emili Darder Primary Health Centre, Palma de Mallorca, Baleares, Spain. ${ }^{7}$ Primary Care Madrid Department, Aspes Primary Health Centre, Madrid, Spain. ${ }^{8}$ Primary Care Majorca, Camp Redó Primary Health Centre, Palma de MallorcaBaleares, Spain.

Received: 5 November 2012 Accepted: 2 February 2013 Published: 11 February 2013

\section{References}

1. Miravitlles M, Soriano JB, Garcia-Rio F, Munoz L, Duran-Tauleria E, Sanchez G, et al: Prevalence of COPD in Spain: impact of undiagnosed COPD on quality of life and daily life activities. Thorax 2009, 64:863-868.

2. Global Strategy for the Diagnosis, Management and Prevention of COPD: Global Initiative for Chronic Obstructive Lung Disease (GOLD) 2011. Available from: http://www.goldcopd.org.

3. Peces-Barba G, Barbera JA, Agusti A, Casanova C, Casas A, Izquierdo JL, et al: Guía clínica de diagnostico y tratamiento de la enfermedad pulmonar obstructiva cronica. Sociedad Espanola de Neumologia y Cirugia Toracica (SEPAR) y Asociacion Latinoamericana del Torax (ALAT). Arch Bronconeumol 2008, 44:271-81.

4. Scanlon PD, Connett KE, Waller LA, Altose MD, Bailey WC, Buist AS: Smoking cessation and lung function in mild-to-moderate chronic obstructive pulmonary disease. The Lung Health Study. Am J Respir Crit Care Med 2000, 161:381-390

5. Nici L, Donner C, Wouters E, Zuwallack R, Ambrosino N, Bourbeau J, Carone $M$, et al: American Thoracic Society/European Respiratory Society 
Statement on Pulmonary Rehabilitation. Am J Respir Crit Care Med 2006, 173:1390-1414.

6. Lacasse Y, Goldstein R, Lasserson TJ, Martin S: Pulmonary rehabilitation for chronic obstructive pulmonary disease. Cochrane Database Syst Rev 2006 4:18. CD003793

7. Puhan MA, Gimeno-Santos E, Scharplatz M, Troosters T, Walters EH, Steurer J: Pulmonary rehabilitation following exacerbations of chronic obstructive pulmonary disease. Cochrane Database Syst Rev 2011, 5(10):CD005305.

8. Brooks D, Sottana R, Bell B, Hanna M, Laframboise L, Selvanayagarajah S, Goldstein R: Characterization of pulmonary rehabilitation programs in Canada in 2005. Can Respir J 2007, 14:87-92.

9. Cambach W, Chadwick-Straver RVM, Wagenaar RC, van Keimpema ARJ, Kemper HCG: The effects of a community-based pulmonary rehabilitation programme on exercise tolerance and quality of life: a randomized controlled trial. Eur Respir J 1997, 10:104-113.

10. Hernandez MT, Rubio TM, Ruiz FO, Riera HS, Gil RS, Gómez JC: Results of a home-based training program for patients with COPD. Chest 2000, 118:106-114.

11. Güell R, Casan P, Belda J, Sangenís M, Morante F, Guyatt GH, Sanchis J: Long-term effects of outpatient rehabilitation of COPD: a randomized trial. Chest 2000, 117:976-983.

12. Finnerty JP, Keeping I, Bullough I, Jones J: The effectiveness of outpatient pulmonary rehabilitation in chronic lung disease: a randomized controlled trial. Chest 2001, 119:1705-1710.

13. Man WD, Polkey MI, Donaldson N, Gray BJ, Moxham J: Community pulmonary rehabilitation after hospitalization for acute exacerbations of chronic obstructive pulmonary disease: randomized controlled study. BMJ 2004, 329:1209.

14. Strijbos JH, Postma DS, van Altena R, Gimeno F, Koeter GH: A comparison between an outpatient hospital-based pulmonary rehabilitation program and a home-care pulmonary rehabilitation program in patients with COPD: a follow-up of 18 months. Chest 1996, 109:366-372.

15. Arnardottir RH, Sörensen S, Ringqvist I, Larsson K: Two different training programmes for patients with COPD: a randomized study with 1-year follow-up. Respir Med 2006, 100:130-139.

16. Chavannes NH, Grijsen M, van den Akker M, et al: Integrated disease management improves one-year quality of life in primary care COPD patients: a controlled clinical trial. Prim Care Respir J 2009, 18:171-6.

17. Zakrisson AB, Engfeldta $P$, Hägglundb D, Odencrantsb S, Hasselgrena M, Arned $M$, Theandere K: Nurse-led multidisciplinary programme for patients with COPD in primary health care: a controlled trial. Prim Care Respir J 2011, 20:427-433.

18. Godtfredsen NS, Grann O, Larsen HB, Sørensen TB, Lavesen M, Pors B, Dalsgaard LS, Kristiansen LC, Andersen KK, Dollerup J: Chronic obstructive pulmonary disease (COPD) rehabilitation at primary health-care centres the KOALA project. Clin Respir J 2012, 6:186-92.

19. Berry MJ, Rejeski WJ, Adair NE, Ettinger WH Jr, Zaccaro DJ, Sevick MA: A randomized, controlled trial comparing long-term and short term exercise in patients with chronic obstructive pulmonary disease. J Cardiopulm Rehabil 2003, 23:60-68.

20. Gómez A, Román M, Larraz C, Esteva M, Mir I, Thomás V, Miranda Pacheco EZ, Macho A: Efficacy of respiratory rehabilitation on patients with moderate COPD in primary care and maintenance of benefits at 2 years. Aten Primaria 2006, 38:230-233.

21. Clark CJ, Cochrane L, Mackay E: Low intensity peripheral muscle conditioning improves exercise tolerance and breathlessness in COPD. Eur Respir J 1996, 9:2590-2596.

22. Normandin EA, McCusker C, Connors M, Vale F, Gerardi D, ZuWallack RL: An evaluation of two approaches to exercise conditioning in pulmonary rehabilitation. Chest 2002, 121:1085-1091.

23. Bianchi L, Bruletti G, Battista L, Pagani M, Ambrosino N: Long-term effectiveness of pulmonary rehabilitation in patients with chronic airway obstruction. Eur Respir J 1999, 13:125-132.

24. Güell R, Casan P, Sangenís M, Morante F, Belda J, Guyatt GH: Quality of life in patients with chronic respiratory disease: the Spanish version of the Chronic Respiratory Questionnaire (CRQ). Eur Respir J 1998, 11:55-60.

25. Reardon J, Awad E, Normandin E, Vale F, Clark B, ZuWallack RL: The effect of comprehensive outpatient pulmonary rehabilitation on dyspnea. Chest 1994, 105:1046-1052.

26. Peces-Barba G, Barberà JA, Agustí A, Casanova C, Casas A, Izquierdo JL, Jardim J, López Varela V, Monsó E, Montemayor T, Viejo JL: Diagnosis and management of chronic obstructive pulmonary disease: joint guidelines of the Spanish Society of Pulmonology and Thoracic Surgery (SEPAR) and the Latin American Thoracic Society (ALAT). Arch Bronconeumol 2008, 44:271-281.

27. Redelmeier DA, Bayoumi AM, Goldstein RS, Guyatt GH: Interpreting small differences in functional status: the Six Minute Walk test in chronic lung disease patients. Am J Respir Crit Care Med 1997, 155:1278-1282.

28. Bestall JC, Paul EA, Garrod R, Garnham R, Jones PW, Wedzicha JÁ: Usefulness of the Medical Research Council (MRC) dyspnea scale as a measure of disability in patients with chronic obstructive pulmonary disease. Thorax 1999, 54:581-6.

29. Griffiths TL, Burr ML, Campbell IA, Lewis-Jenkins V, Mullins J, Shiels K, TurnerLawlor PJ, Payne N, Newcombe RG, Ionescu AA, Thomas J, Tunbridge J: Results at 1 year of outpatient multidisciplinary pulmonary rehabilitation: a randomized controlled trial. Lancet 2000, 355:362-8.

30. Ketelaars CA, Abu-Saad HH, Schlösser MA, Mostert R, Wouters EF: Longterm outcome of pulmonary rehabilitation in patients with COPD. Chest 1997, 112:363-9.

31. Moullec G, Ninot G: An integrated programme after pulmonary rehabilitation in patients with chronic obstructive pulmonary disease: effect on emotional and functional dimensions of quality of life. Clin Rehabil 2010, 24:122-36.

32. Karapolat H, Atasever A, Atamaz F, Kirazli J, Elmas F, Erdinç E: Do the benefits gained using a short-term pulmonary rehabilitation program remain in COPD patients after participation? Lung 2007, 185:221-225.

33. Riario-Sforza GG, Incorvaia C, Paterniti F, Pessina L, Caligiuri R, Pravettoni C, Di Marco F, Centanni S: Effects of pulmonary rehabilitation on exercise capacity in patients with COPD: a number needed to treat study. Int J Chron Obstruct Pulmon Dis 2009, 4:315-319.

34. Kruis AL, van Adrichem J, Erkelens MR, Scheepers $H$, In 't Veen H, Muris JW Chavannes NH: Sustained effects of integrated COPD management on health status and exercise capacity in primary care patients. Int J Chron Obstruct Pulmon Dis 2010, 5:407-13.

35. Engström CP, Persson LO, Larsson S, Sullivan M: Long-term effects of a pulmonary rehabilitation programme in outpatients with chronic obstructive pulmonary disease: a randomized controlled study. Scand J Rehabil Med 1999, 31:207-213.

36. Hoogendoorn M, van Wetering CR, Schols AM, Rutten-van Mölken MP: Is INTERdisciplinary Community-based COPD management (INTERCOM) cost effective? Eur Respir J 2010, 35:79-87.

37. Maltais F, Bourbeau J, Shapiro S, Lacasse $Y$, Perrault $H$, Baltzan M, Hernandez P, Rouleau M, Julien M, Parenteau S, Paradis B, Levy RD, Camp P, Lecours R, Audet R, Hutton B, Penrod JR, Picard D, Bernard S: Effects of home-based pulmonary rehabilitation in patients with chronic obstructive pulmonary disease: a randomized trial. Ann Intern Med 2008, 149:869-878.

38. Wempe JB, Wijkstra PJ: The impact of rehabilitation on behavior modification in COPD. Pat Educ Counseling 2004, 52:327-41.

39. Turnock AC, Walters EH, Walters JAE, Wod-Baker R: Action plans for chronic obstructive pulmonary disease. Cochrane Database Systc Rev 2005, 19(4): CD005074.

40. de Miguel DJ, Izquierdo Alonso JL, Molina París J, Bellón Cano JM, Rodríguez González-Moro JM, de Lucas RP: Factors affecting drug prescription in patients with stable COPD: results from a multicenter Spanish study (IDENTEPOC). Arch Bronconeumol 2005, 41:63-70.

41. Faulkner J, Walshaw E, Campbell J, Jones R, Taylor R, Price D, Taylor AH: The feasibility of recruiting patients with early COPD to a pilot trial assessing the effects of a physical activity intervention. Prim Care Respir J 2010, 19:124-130.

42. Steele BG, Belza B, Cain KC, Coppersmith J, Lakshminarayan S, Howard J, Haselkorn JK: A randomized clinical trial of an activity and exercise adherence intervention in chronic pulmonary disease. Arch Phys Med Rehabil 2008, 89:404-412.

doi:10.1186/1471-2296-14-21

Cite this article as: Román et al:: Efficacy of pulmonary rehabilitation in patients with moderate chronic obstructive pulmonary disease: a randomized controlled trial. BMC Family Practice 2013 14:21. 